\title{
PRÓPOLIS PRODUZIDA NO SUL DO BRASIL, ARGENTINA E URUGUAI: EVIDÊNCIAS FITOQUÍMICAS DE SUA ORIGEM VEGETAL
}

\author{
PROPOLIS PRODUCED IN SOUTH BRAZIL, ARGENTINE AND URUGUAY: \\ PHYTOCHEMICAL EVIDENCE FOR THE PLANT ORIGIN
}

\author{
Yong Kun Park $^{1}$ Severino Matias Alencar ${ }^{2}$ Adilma Regina Pippa Scamparini ${ }^{3}$ \\ Claudio Lima Aguiar ${ }^{4}$
}

\section{RESUMO}

A própolis é uma substância resinosa coletada pelas abelhas de diversas partes da planta. Sua composição depende da época, vegetação e área de coleta. Própolis produzida por abelhas Apis mellifera africanizada do sul do Brasil, Argentina e Uruguai foram investigadas por meio de técnicas cromatográficas. De acordo com os resultados obtidos por CCDAE-FR, CLAE-FR e CG-EM, as própolis do sul do Brasil foram classificadas em 5 grupos distintos. Com base nas evidencias fitoquímicas, Populus alba foi identificada como a principal fonte da própolis do grupo 3 do sul do Brasil, Argentina e Uruguai.

Palavras-chave: própolis, origem botânica, Populus alba, compostos fenólicos.

\section{SUMMARY}

Propolis is a resinous hive product collected by honeybees from plant source. The composition of the propolis depends upon the time, vegetation and the area of collection. Propolis produced by africanized Apis mellifera from south Brazil, Argentine and Uruguay have been investigated using chromatographic techniques. In accordance with results $R P$ HPTLC, RP-HPLC, and GC-MS, propolis from south Brazil were classified IN 5 groups. Based on chemical evidence Populus alba was shown to be the main propolis source of group 3 from south Brazil, Argentine and Uruguay.

Key words: propolis, botanical origin, Populus alba, phenolic compounds.

\section{INTRODUÇÃO}

A própolis é uma substância resinosa, coletada pelas abelhas Apis mellifera, de diversas partes da planta como broto, botões florais e exsudatos resinosos. A sua composição química é bastante complexa e variada, estando intimamente relacionada com a ecologia da flora de cada região visitada pelas abelhas. De modo geral, contém 50$60 \%$ de resinas e bálsamos, 30-40\% de ceras, 5-10\% de óleos essenciais, $5 \%$ de grãos de pólen, além de microelementos como alumínio, cálcio, estrôncio, ferro, cobre, manganês e pequenas quantidades de vitaminas $\mathrm{B}_{1}, \mathrm{~B}_{2}, \mathrm{~B}_{6}, \mathrm{C}$ e E (GHISALBERTI, 1979). A própolis é conhecida, principalmente, por suas propriedades antimicrobiana, antioxidante, antiinflamatória, imunomodulatória, hipotensiva, cicatrizante, anestésica, anticâncer, anti-HIV e anticariogênica (GHISALBERTI, 1979; BANKOVA et al., 1989; PARK \& IKEGAKI, 1998; PARK et al., 1998; PARK et al., 2000; ISLA et al., 2001).

Na Europa, América do Norte e oeste da Ásia, a fonte dominante de própolis é o exsudato do botão de álamo (Populus sp.) (MARKHAM et al., 1996; WOLLENWEBER \& BUCHMANN, 1997). Entretanto, na América do Sul a espécie vegetal do gênero Populus não é nativa, existindo uma grande

\footnotetext{
${ }^{1}$ Médico, Professor Titular, Faculdade de Engenharia de Alimentos, Universidade Estadual de Campinas (UNICAMP), CP 6177, 13083970, Campinas, SP. E-mail: ykpark@fea.unicamp.br. Autor para correspondência.

${ }^{2}$ Engenheiro Agrônomo, MSc., Doutorando em Ciências de Alimentos, Faculdade de Engenharia de Alimentos, UNICAMP.

${ }^{3}$ Engenheira de Alimentos, Professora Convidada de Química de Alimentos, Faculdade de Engenharia de Alimentos, UNICAMP.

${ }^{4}$ Engenheiro Químico, MSc., Doutorando em Ciências de Alimentos, Faculdade de Engenharia de Alimentos, UNICAMP.
} 
diversidade vegetal para a retirada de resina, o que dificulta a correlação da própolis com a fonte produtora. A dependência geográfica e vegetal da própolis é exemplificada nas análises de própolis da América do Sul, Europa, China, Canadá e Espanha (KÖNIG, 1985; GREENAWAY et al., 1990; GARCIA-VIGUERA et al., 1992; TOMASBARBERAN et al., 1993; BONVEHI \& COLL, 1994; PARK et al., 1998; PARK et al., 2000).

O melhor indicador da origem botânica da própolis é a análise da sua composição química comparada com a provável fonte vegetal. A determinação da origem geográfica e, principalmente, a origem vegetal, aliada à fenologia da planta hospedeira, se faz importante no controle de qualidade e até mesmo na padronização das amostras de própolis para uma efetiva aplicação terapêutica.

O objetivo deste trabalho foi avaliar a composição química e a origem botânica da própolis de Apis mellifera da região Sul do Brasil, Argentina e Uruguai por meio de técnicas cromatográficas como, CCDAE-FR, CLAE-FR e CG-EM.

\section{MATERIAL E MÉTODOS}

As amostras de própolis de abelhas africanizadas (A. mellifera) foram coletadas no Sul do Brasil, Argentina e Uruguai, num total de 150 amostras, conforme apresentado nas tabelas 1 e 2 .

A resina vegetal de álamo (P. alba) foi coletada em Santa Cruz do Timbó, no Estado de Santa Catarina. Os extratos etanólicos de própolis (EEP) foram preparados a partir da adição de $15 \mathrm{~m} \ell$ de etanol $(80 \%)$ a 2 gramas de própolis triturada e

Tabela 1 - Distribuição das amostras de própolis coletadas.

\begin{tabular}{|c|c|c|c|}
\hline \multirow{3}{*}{$\begin{array}{l}\text { País } \\
\text { Argentina }\end{array}$} & \multicolumn{2}{|r|}{ Município } & $\begin{array}{l}\text { Número de } \\
\text { amostras }\end{array}$ \\
\hline & \multicolumn{2}{|r|}{ Buenos Aires } & 2 \\
\hline & \multicolumn{2}{|r|}{ Tucumán } & 11 \\
\hline \multirow[b]{3}{*}{ Brasil } & Rio Grande do Sul & $\begin{array}{c}\text { Alegrete, Bagé, Barracão, Bom Jesus, } \\
\text { Cambará do Sul, Camaquã, Caxias do Sul, } \\
\text { Gramado, Jaguari, Lagoa Vermelha, Pelotas, } \\
\text { Santiago, São Francisco de Paula, Taquara }\end{array}$ & 43 \\
\hline & Santa Catarina & $\begin{array}{c}\text { Irineópolis, Porto União, Santa Cruz do } \\
\text { Timbó }\end{array}$ & 11 \\
\hline & Paraná & $\begin{array}{l}\text { Agudos do Sul, Antônio Olinto, Bocaiúva do } \\
\text { Sul, Campina Grande do Sul, Cândido de } \\
\text { Abreu, Candoi, Chopinzinho, Clevelândia, } \\
\text { Cruz Machado, Curitiba, General Carneiro, } \\
\text { Imbituva, Itapejara do Sul, Lapa, Madirituba, } \\
\text { Mariópolis, Palmeiras, Pato Branco, Paula } \\
\text { Freire, Paulo Fontin, Prudentópolis, Quatro } \\
\text { Barras, Quitandinhas, Reserva, Tibagi, Tunas } \\
\text { da Vitória, União da Vitória }\end{array}$ & 75 \\
\hline Uruguai & & Montevidéu & 8 \\
\hline
\end{tabular}

homogeneizada. A extração foi feita a $70^{\circ} \mathrm{C}$ por 30 minutos e sob agitação constante. Após isso, foi feita uma centrifugação a $7500 \mathrm{x} \mathrm{g}$, a $5^{\circ} \mathrm{C}$ por 10 minutos e o sobrenadante transferido para tubos de ensaio (15 x 160mm). Ao resíduo do tubo de centrífuga, adicionaram-se $10 \mathrm{~m} \ell$ de etanol $(80 \%)$, sendo feita mais uma extração. Os sobrenadantes obtidos foram homogeneizados e acondicionados a $5^{\circ} \mathrm{C}$. Os extratos metanólicos de álamo (P. alba) foram obtidos pela extração de 5 gramas de botões florais em $20 \mathrm{~m} \ell$ de metanol P.A. durante 30 minutos a $60^{\circ} \mathrm{C}$, seguida de centrifugação a $7500 \mathrm{x} \mathrm{g}$, a $5^{\circ} \mathrm{C}$ por 10 minutos. Os sobrenadantes obtidos foram homogeneizados e acondicionados a $5^{\circ} \mathrm{C}$.

A cromatografia em camada delgada de alta eficiência dos extratos alcoólicos foi feita de acordo com os métodos descritos por PARK et al. (1995) e PARK $\boldsymbol{e t}$ al. (1997), onde $3 \mu \ell$ dos EEP e metanólicos de $\boldsymbol{P}$. alba foram aplicados em placas $\mathrm{RP} 18 \mathrm{~F}_{254} \mathrm{~S}$ (Merck Co.). Utilizou-se como sistema solvente etanol:água destilada $(55: 45, \mathrm{v} / \mathrm{v})$. As placas desenvolvidas foram observadas sob luz ultravioleta $(366 \mathrm{~nm})$.

As análises dos extratos alcoólicos por cromatografia líquida de alta eficiência em fase reversa foram feitas de acordo com o método modificado de PARK et al. (1997) e KOO et al. (2000), NO QUAL $20 \mu \ell$ do extrato foram injetados em cromatógrafo líquido acoplado a um detector de arranjo de fotodiodos a $254 \mathrm{~nm}$ e uma coluna de fase reversa YMC PACK ODS $(250 \times 4,6 \mathrm{~mm})$. A fase móvel utilizada foi água/ácido acético $(19: 1$, v/v) (solvente A) e metanol (solvente B), com fluxo constante de $1 \mathrm{~m} \ell / \mathrm{min}$. O gradiente iniciou com $30 \%$ do solvente B até $40 \%$ de B em 15 minutos, $50 \%$ de $\mathrm{B}$ em 30 minutos, $60 \%$ de $\mathrm{B}$ em 45 minutos, $75 \%$ de B em 65 minutos, $75 \%$ de B em 85 minutos, $90 \%$ de $\mathrm{B}$ em 95 minutos e $30 \%$ de B em 105 minutos. A coluna foi mantida a uma temperatura constante de $35^{\circ} \mathrm{C}$ e os cromatogramas foram processados utilizando-se "software" específico. Os compostos foram identificados pelo espectro de absorção na região ultravioleta, utilizandose os recursos do detector de arranjo de fotodiodos (SPDM10A, Shimadzu Co.), pela comparação do tempo de retenção e co-cromatografia de padrões. Foram utilizados padrões autênticos de flavonóides e ácidos fenólicos (Extrasynthese Co.). Adicionalmente, pinobanksina, pinobanksina-3-acetato e o éster do ácido dimetil dialil caféico foram gentilmente cedidos pelo Dr. Eckhard Wollenweber, do Intitut für

Ciência Rural, v. 32, n. 6, 2002. 
Tabela 2 - CG - EM dos cinco grupos de própolis da região Sul do Brasil.

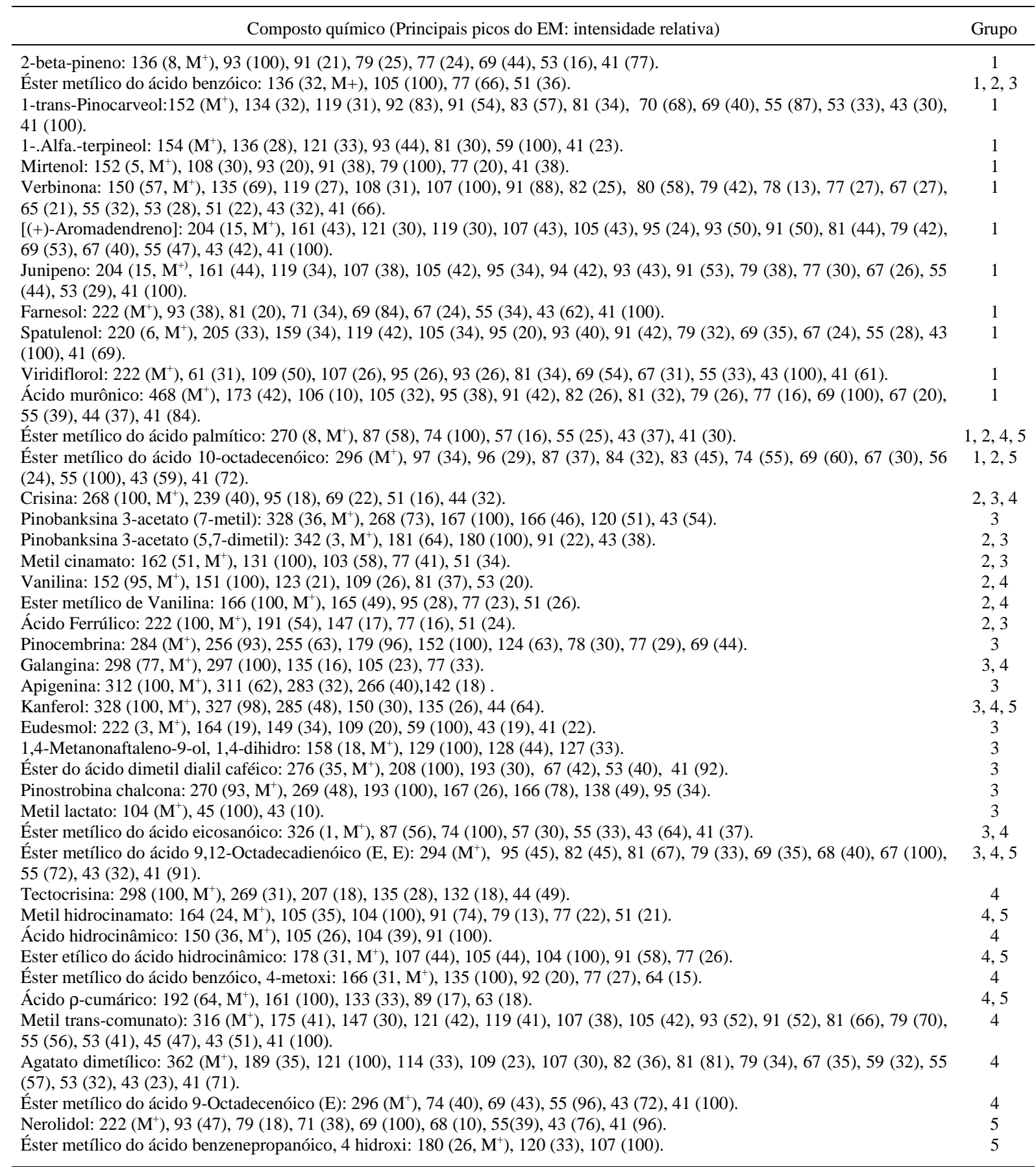

Botanik der Technischen Hochschule, Darmstadt, Alemanha.

Às alíquotas de $400 \mu \ell$ dos extratos alcoólicos, foi adicionado $1 \mathrm{~m} \ell$ de solução etérea de diazometano $\left(\mathrm{CH}_{2} \mathrm{~N}_{2}\right)$ para a metilação. As amostras permaneceram em banho de gelo por 4 horas para a completa metilação. Após este tratamento, adicionaram-se $300 \mu \ell$ de diclorometano $\left(\mathrm{CH}_{2} \mathrm{Cl}_{2}\right)$ e filtraram-se as amostras. As amostras foram analisadas em cromatógrafo gasoso CG 17A (Shimadzu Co.) acoplado a um espectrômetro de massas QP 5000 (Shimadzu Co.) equipado com uma coluna capilar CBP5 30m x 0,25mm e um dectetor operando no modo scanning $(\mathrm{m} / \mathrm{z}$ 40-400). A programação de temperatura foi $50^{\circ} \mathrm{C}(0,3 \mathrm{~min})$ a $285^{\circ} \mathrm{C}$ (15min), com um incremento de $6^{\circ} \mathrm{C} / \mathrm{min}$. As 
amostras $(0,6 \mu \ell)$ foram injetadas por auto-injetor AOC-17, com injeção splitless. A integração foi feita através do software específico do equipamento (QP5000 software). Flavonóides e ácidos fenólicos presentes foram identificados por comparação com os dados obtidos do CG-EM (tempo de retenção e fragmentação iônica) de padrões autênticos metilados e eluídos nas mesmas condições. Outros compostos foram identificados por comparação com os dados do espectro de massas da biblioteca do equipamento (Willey139-Shimadzu).

\section{RESULTADOS E DISCUSSÃO}

Após o processamento e análise das amostras de própolis coletadas na região Sul do Brasil, quanto ao perfil cromatográfico em camada delgada de alta eficiência (CCDAE) e cromatografia gasosa com espectrometria de massas (CG-EM), foi possível a classificação em 5 grupos distintos (Tabela 2 e Figura 1). Apesar da existência de outros tipos de própolis nesta região, estes não foram incluídos devido a sua rara ocorrência. PARK et al. (2000) relataram a existência de 12 grupos de própolis brasileiras, sendo que na região Sudeste foi encontrado apenas um grupo, demonstrando assim que as amostras da região Sul do Brasil apresentam uma maior diversidade vegetal para a retirada de resina pelas abelhas, muito embora durante este trabalho apenas um grupo pode ter sua origem

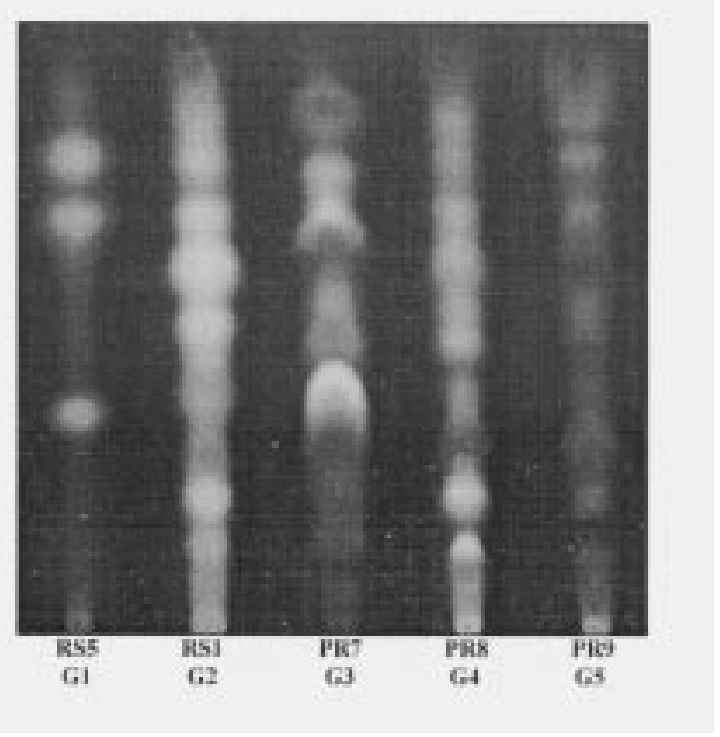

Figura 1 - Cromatografia em camada delgada de alta eficiência (CCDAE), irradiada a 366nm, dos extratos etanólicos dos cinco grupos de própolis do sul do Brasil . G1 = grupo 1; G2 = grupo 2; G3 = grupo 3; G4 = grupo $4 \mathrm{e}$ $\mathrm{G} 5=$ grupo 5 vegetal elucidada, sendo este classificado como grupo 3. Conforme mostrado nos dados de CG-EM (Tabela 2) pode-se observar que cada tipo de própolis possui uma composição química particular, não sendo encontrado nenhum composto que fosse comum aos 5 grupos, muito embora, hajam compostos como o éster metílico do ácido palmítico, o éster metílico do ácido 9,12-octadecadienóico, a crisina e o kanferol, que tenham sido observados em grande parte dos grupos.

Quando se observa a CCDAE das amostras do grupo 3 (Santa Cruz do Timbó/SC), Uruguai (Montevidéu) e Argentina (Buenos Aires e Tucumán) (Figura 2), verifica-se o mesmo perfil cromatográfico, apesar da cromatografia em camada delgada da amostra de Tucumán mostrar uma banda mais escura no início da corrida. Entretanto, a análise realizada por CLAE (Figura 3) confirma a existência dos mesmos compostos fenólicos, variando somente a sua proporção. Isto pode ser explicado em parte, pela mudança climática, a qual pode causar uma certa oscilação na proporção dos componentes da fonte vegetal primária em cada estação do ano, visto que as amostras da Argentina e do Uruguai não foram coletadas na mesma época que as amostras brasileiras. Todos estes resultados sugerem a mesma fonte vegetal para a origem deste tipo de própolis. A própolis do grupo 3 e a resina

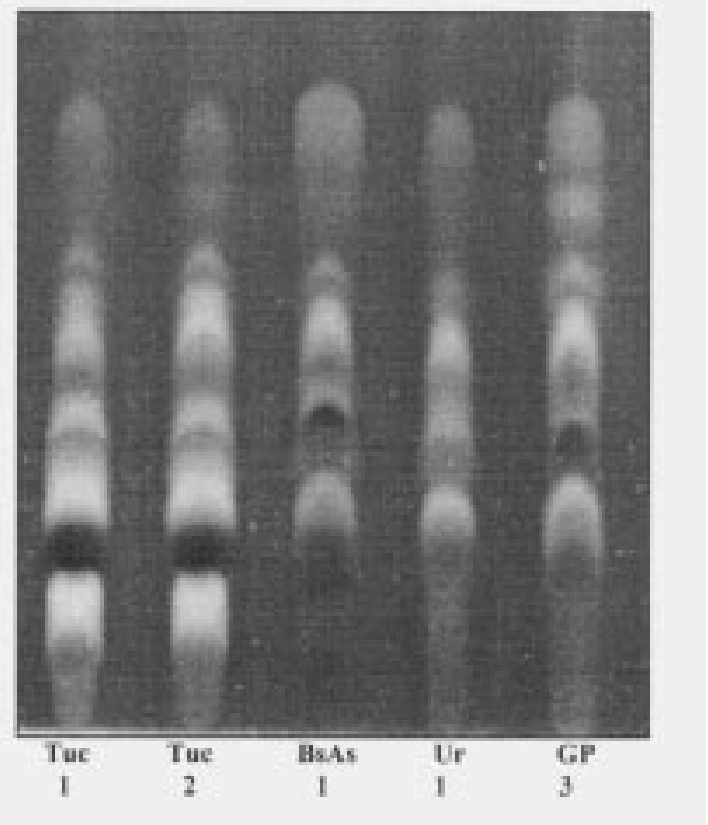

Figura 2 - Cromatografia em camada delgada de alta eficiência (CCDAE) dos extratos etanólicos de própolis. (Tuc $=$ Tucumán; BsAs = Buenos Aires; Ur = Uruguai; GP3 = grupo 3 ).

Ciência Rural, v. 32, n. 6, 2002. 


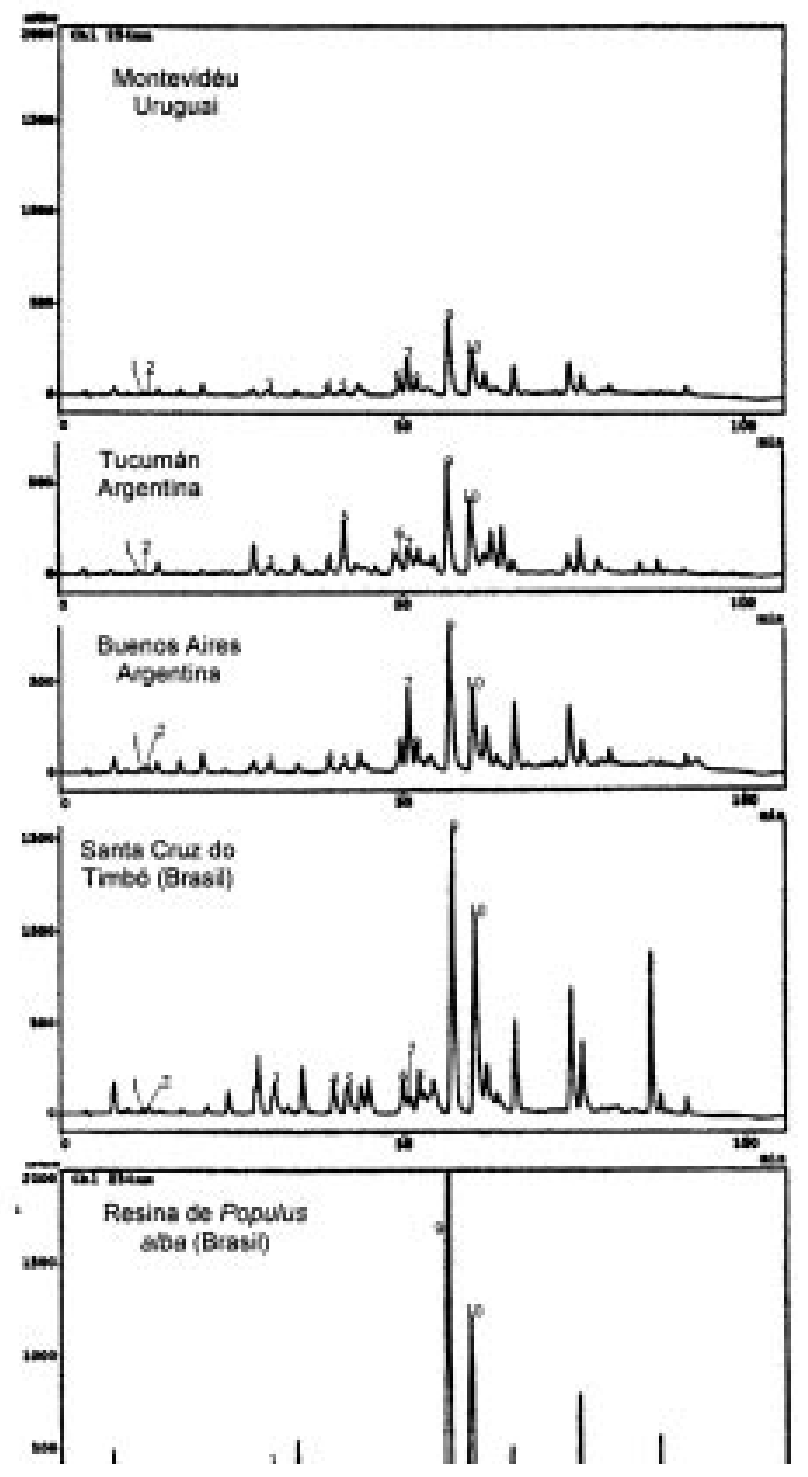

Figura 3 - Cromatografia líquida de alta eficiência dos extratos etanólicos de própolis e metanólico de álamo (1=ácido cumárico; 2=ácido ferrúlico; 3=pinobanksina; 4=Kanferol; 5=apigenina; $6=$ pinocembrina; $7=$ éster do ácido dimetil dialil caféico; 8=Pinobanksina-3-acetato; 9=crisina;

vegetal de $\boldsymbol{P}$. alba (álamo) foram coletadas na região Sul do Brasil, perto da divisa do Paraná com Santa Catarina, especificamente na cidade de Santa Cruz do Timbó. Nesta região, existem diversas áreas de reflorestamento cultivadas com uma espécie de álamo, que foi trazida da Europa por descendentes alemães e que dá origem a um tipo de própolis bastante comum em países de clima temperado. $\mathrm{O}$ extrato metanólico da resina álamo foi analisado por cromatografia líquida de alta eficiência (Figura 3) e cromatografia gasosa acoplada com espectrômetro de massas. A análise por CG-EM, da resina de álamo e da própolis do grupo 3, apresentou da mesma forma que a CLAE, o mesmo padrão de composição química (Figura 4). Através do uso destas técnicas cromatográficas (CLAE e CG-EM) foi possível identificar e confirmar a presença do éster do ácido dimetil dialil caféico, o qual é um composto altamente alergênico, sendo encontrado em própolis de clima temperado cuja origem vegetal tenha sido Populus sp. (WOLLENWEBER $\boldsymbol{e t} \boldsymbol{a l}$., 1987). De acordo com os resultados obtidos pela técnica de CG-EM, pode-se dizer que o grupo 3 é quimicamente similar à resina de álamo, tendo possivelmente a sua origem nesta espécie vegetal. De fato, os flavonóides, crisina e galangina, encontrados em todas as amostras são característicos de própolis oriundas de árvores da espécie Populus sp. (BANKOVA et al., 1987; WOLLENWEBER et al., 1987). Apesar desta espécie vegetal $\boldsymbol{P}$. alba não ser nativa dos trópicos, ela pode existir em algumas regiões de clima ameno, como o sul do Brasil e outros países fronteiriços de clima temperado, fazendo com que abelhas retirem preferencialmente a resina deste vegetal para elaboração da própolis.

\section{CONCLUSÕES}

A região Sul do Brasil apresenta uma grande diversidade vegetal, para a retirada de resinas pelas abelhas, possibilitando a ocorrência de 5 grupos distintos de própolis de grande freqüência, e dentre estes grupos foi possível identificar a origem vegetal do grupo 3. Ficou comprovada que a origem botânica da própolis deste grupo, da Argentina e do Uruguai, é a espécie vegetal $\boldsymbol{P}$. alba, segundo os perfis fitoquímicos comparativos. 

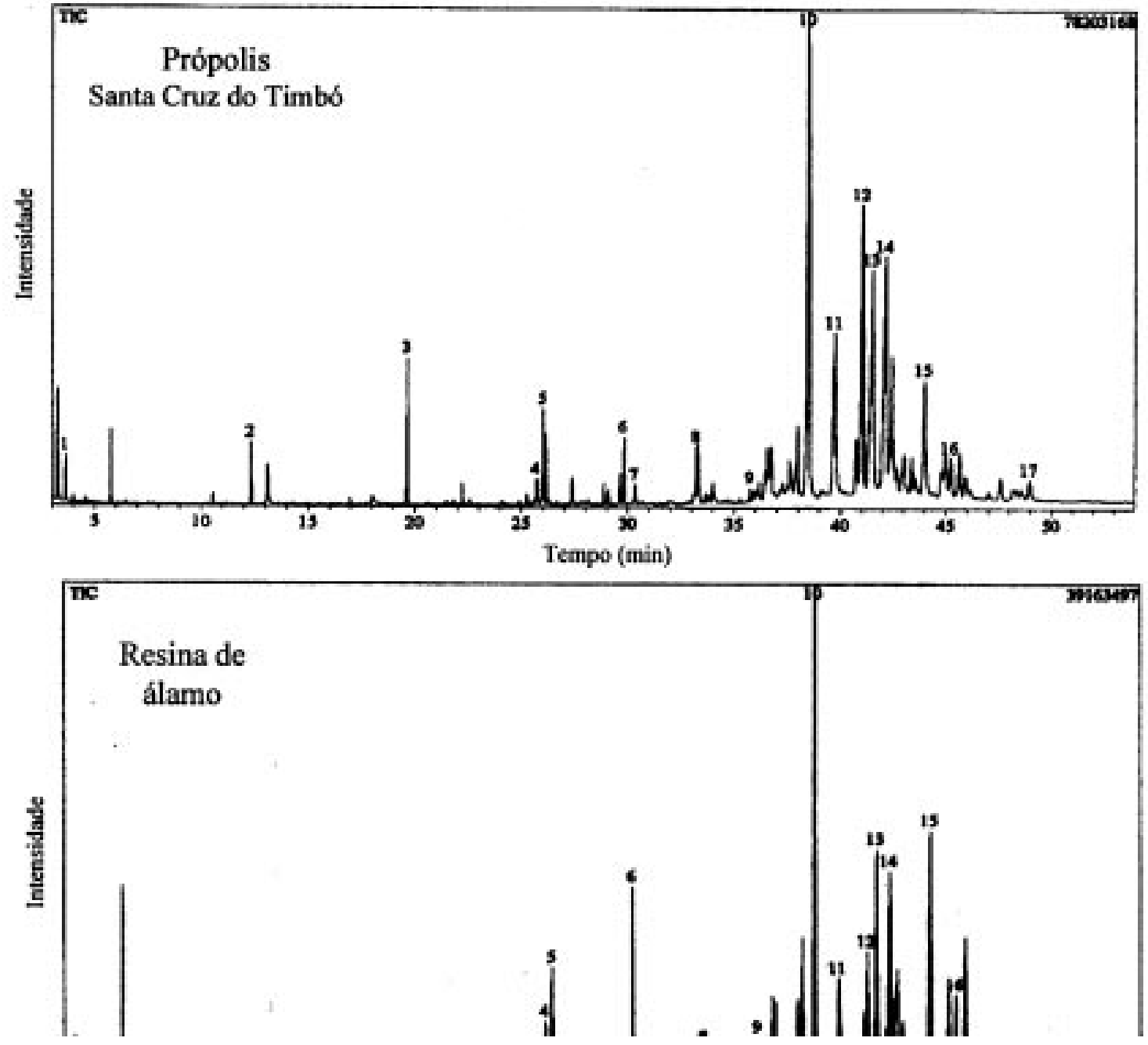

Figura 4 - Cromatografia gasosa acoplada com espectrômetro de massas da própolis do grupo 3 e resina de P. alba (pico 1- metil lactato (éster metílico do ácido propanóico-2 hidroxi): $104\left(\mathrm{M}^{+}\right), 45$ (100), 43 (10); pico 2- éster metílico do ácido benzóico: 136 (32, $\mathrm{M}^{+}$), 105 (100), 77 (66), 51 (36); pico 3- metil cinamato (éster metílico do ácido cinâmico): 162 (51, M+), 131 (100), 103 (58), 102 (17), 77 (41), 51 (34); pico 4- Eudesmol: 222 (3, M+), 164 (19), 149 (34), 109 (20), 59 (100), 43 (19), 41 (22); pico 5 - 1,4Metanonaftaleno-9-ol, 1,4-dihidro: $158\left(18, \mathrm{M}^{+}\right), 129$ (100), 128 (44), 127 (23); pico 6- ácido ferrúlico (etil 3,4dimetoxicinamato): $222\left(100, \mathrm{M}^{+}\right), 191$ (54), 147 (17), 77 (16), 51 (24); pico 7- éster metílico do ácido eicosanóico: 326 (1, $\mathrm{M}^{+}$), 87 (56), 74 (100), 57 (30), 55 (33), 43 (64), 4 (37); pico 8- éster metílico do ácido 9,12-octadecadienóico: 294 (M $\left.{ }^{+}\right), 95$ (45), 82 (45), 81 (67), 79 (33), 69 (35), 68 (40), 67 (100), 55 (72), 54 (38), 43 (32), 41 (91); pico 9- éster do ácido dimetil dialil caféico: $276\left(35, \mathrm{M}^{+}\right), 208$ (100), 193 (30), 67 (42), 53 (40), 41 (92); pico 10- pinostrobina chalcona (2-propen-1-one, 1(2,6-dihidroxi-4-metoxifenil)-3-fenil-, (E)): 270 (93, M+), 269 (48), 193 (100), 167 (26), 166 (78), 138 (49), 95 (34); pico 11 pinocembrina (pinocembrina 5,7-dimetil éter): $284\left(\mathrm{M}^{+}\right), 256$ (93), 255 (63), 179 (96), 152 (100), 124 (63), 78 (30), 77 (29), 69 (44); pico 12- pinobansina 3-acetato (pinobansina 3-acetato 7-metil éter): $328\left(36, \mathrm{M}^{+}\right), 268$ (73), $167(100), 166(46), 120$ (51), 43 (54); pico 13- crisina (crisina 7-metil éter): 268 (100, $\left.\mathrm{M}^{+}\right), 239$ (40), 95 (18), 69 (22), 51 (16), 44 (32); pico 14- galangina (galangina 7-metil éter): $298\left(77, \mathrm{M}^{+}\right), 297(100), 135(16), 105$ (23), 77 (33); pico 15- pinobansina 3-acetato (pinobansina 3-acetato 5,7-dimetil éter): $342\left(3, \mathrm{M}^{+}\right), 181(64), 180(100), 91(22), 43(38)$; pico 16-apigenina (trimetil apigenina,4,5,7trimetoxiflavona): $312\left(100, \mathrm{M}^{+}\right), 311$ (62), 283 (32), 266 (40), 239 (14), 142 (18); pico 17- kanferol: 328 (100, $\left.\mathrm{M}^{+}\right), 327$ (98), $285(48), 150(30), 135(26), 44(64))$

\section{AGRADECIMENTOS}

Os autores agradecem ao Sr. Henrique F. E. Breyer, pelo fornecimento de algumas amostras de própolis e material vegetal para os estudos físico-químicos, e à Fundação de Amparo à Pesquisa do Estado de São Paulo (FAPESP), pelo suporte financeiro.

\section{REFERÊNCIAS BIBLIOGRÁFICAS}

BANKOVA, V.S., POPOV, S.S., MAREKOV, N.L. Isopentenyl cinnamates from poplar buds and propolis. Phytochem, v.28, n.3, p.871-873, 1989 .

Ciência Rural, v. 32, n. 6, 2002. 
BANKOVA, V, DYUlGEROV, A., POPOV, S., et al. A.G.C. MS study of the propolis phenolic constituents. $\mathbf{Z}$ Naturforsch, v.42c, n.1-2, p.147-151, 1987.

BONVEHI, J.S., COLL, F.V. Phenolic composition of propolis from China and from South-America. Z Naturforsch, v.49c, p.712-718, 1994.

GARCIA-VIGUERA, C., GREENAWAY, W., WHATLEY, F.R. Composition of propolis from 2 different Spanish regions. $\mathbf{Z}$ Naturforsch, v.47c, n.7-8, p.634-637, 1992.

GHISALBERTI, E.L. Propolis: A review. Bee World, v.60, p.59-84, 1979.

GREENAWAY, W., SCAYSBROOK, T., WHATLEY, F.R. The composition and plant origins of propolis. Bee World, v.71, n.3, p.107-118, 1990

ISLA, M.I., MORENO, M.I.N., SAMPIETRO, A.R., et al. Antioxidant activity of Argentine propolis extracts. J Ethnopharmacol, v.76, n.2, p.165-170, 2001.

KÖNIG, B. Plant sources of propolis. Bee World, v. 66, p.136 139,1985

KOO, H., ROSALEN, P.L., CURY, J.A., et al. Effect of a new variety of Apis mellifera propolis on mutans streptococci. Curr Microbiol, v.41, n.3, p.192-196, 2000.

MARKHAM, R.K., MITCHELL, K.A., WILKINS, A.L., et al. HPLC and GC-MS identification of the major organic constituints in New Zeland propolis. Phytochem, v.42, n.1, p.205-211, 1996
PARK, Y.K., IKEGAKI, M. Preparation of water and ethanolic extracts of propolis and evaluation of the preparations. Biosci Biotechnol Biochem, v.62, p.2230-2232, 1998.

PARK, Y.K., IKEGAKI, M., ALENCAR, S.M., et al. Evaluation of Brazilian propolis by both physicochemical methods and biological activity. Honeybee Sci, v.21, n.2, p.85-90, 2000.

PARK, Y.K., KOO, M.H., IKEGAKI, M., et al. Comparision of the flavonoid aglycone contents of Apis mellifera propolis from various regions of Brazil. Arq Biol Tecnol, v.40, n.1, p.97-106, 1997.

PARK, Y.K., KOO, M.H., SATO, H.H., et al. Estudo de alguns componentes da própolis coletada por Apis mellifera no Brasil. Arq Biol Tecnol, v.38, n.4, p.1253-1259, 1995.

PARK, Y.K., KOO, M.H., ABREU, J.A.S., et al. Antimicrobial activity of propolis on oral microrganism. Current Microbiol, v.34, n.1, p.24-28, 1998.

TOMAS-BARBERAN, F.A., GARCÍA-VIGUERA, C., VITOLIVIER, P., et al. Phytochemical evidence for the botanical origin of tropical propolis from Venezuela. Phytochem, v.34, n.1, p.191-196, 1993.

WOLLENWEBER, E., ASAKAWA, Y., SCHILLO, D., $\boldsymbol{e}$ t al. A novel caffeic acid derivative and other constituents of Populus bud excretion and propolis (bee-glue). $\mathbf{Z}$ Naturforsch, v.42c, n.9-10, p.1030-1034, 1987.

WOLLENWEBER, E., BUCHMANN, S. L. Feral honeybees in the Sonoran Desert: Propolis sources other than poplars (Populus spp.). Z Naturforsch, v.52C, n.7-8, p.530-535, 1997. 